\title{
Treatment of Advanced Epithelial Ovarian Cancer
}

\author{
a report by \\ Joyce Liu, MD' and Ursula Matulonis, MD² \\ 1. Clinical Fellow, Adult Oncology, 2. Director, Medical Gynecologic Oncology, Department of Oncology, Dana \\ Farber Cancer Institute
}

DOI: $10.17925 /$ OHR.2006.00.02.57

Ovarian cancer remains the leading cause of death among women with gynecological malignancies and the fifth leading cause of cancer mortality in women in the US. In the most recent cancer statistics released by the American Cancer Society, it is estimated that there will be 20,180 new cases of ovarian cancer in 2006, with an estimated 15,310 deaths. ${ }^{1}$ Globally, there were 204,000 new cases of ovarian cancer in 2002, with nearly 125,000 deaths. $^{2}$ Approximately $75 \%$ of all patients with ovarian cancer will present with either stage III or stage IV disease. In this article, we will discuss the management options for patients with newly diagnosed advanced epithelial ovarian cancer and for those with recurrent ovarian cancer.

\section{Cytoreductive Surgery}

Cytoreductive surgery has played an important role in the management of advanced ovarian cancer since Griffiths demonstrated in 1975 that an inverse relationship existed between overall survival and residual tumor size. ${ }^{3}$ This has been confirmed in subsequent studies, and a meta-analysis of 81 cohorts of patients with stage III or IV disease from clinical trials conducted between 1989 and 1998 suggested that for every $10 \%$ increase in the proportion of patients achieving maximal cytoreduction-defined in this meta-analysis as residual disease $\leq 3 \mathrm{~cm}$ in maximal dimension-there was an approximate $5.5 \%$ improvement in length of overall survival. ${ }^{4}$ The definition of optimal debulking has been discussed in the literature. A 2001 survey of gynecological oncologists revealed that $12 \%$ defined optimal reduction as no residual disease, $13.7 \%$ used a $5 \mathrm{~mm}$ minimum threshold, $60.8 \%$ used a $1 \mathrm{~cm}$ threshold, and $12.6 \%$ used a $1.5-2 \mathrm{~cm}$ threshold. ${ }^{5}$ Currently, a widely accepted Gynecologic Oncology Group (GOG) definition states that optimal cytoreduction surgery leaves less than $1 \mathrm{~cm}$ in maximum residual cancer. ${ }^{6}$

\section{Intra-peritoneal Chemotherapy}

The concept of intra-peritoneal (IP) chemotherapy for ovarian cancer involves the regional delivery of cytotoxic drugs directly into the peritoneal cavity, resulting in higher concentrations than can be safely reached with systemic intravenous chemotherapy alone, a hypothesis that has been confirmed in pharmacokinetic studies. ${ }^{7}$ Three US-based phase III clinical trials have now evaluated the efficacy of IP therapy in optimally cytoreduced advanced ovarian cancer. The first of these trials enrolled 654 patients with stage III disease and who were optimally cytoreduced to residual cancer of $\leq 2$ centimeters. ${ }^{8}$ Patients were randomized to either intravenous (IV) cyclophosphamide $600 \mathrm{mg} / \mathrm{m}^{2}$ and IV cisplatin $100 \mathrm{mg} / \mathrm{m}^{2}$ or intravenoous (IV) cyclophosphamide $600 \mathrm{mg} / \mathrm{m}^{2}$ and IP cisplatin $100 \mathrm{mg} / \mathrm{m}^{2}$. In this trial, the median survival of the IP group was 49 months and that of the IV group 41 months, with a hazard ratio for death of 0.72 in the IP group $(p=0.02)$. However, the benefit of IP cisplatin was questioned because paclitaxel was not given as part of either regimen.

Markman et al. in 2001 randomized 523 patients with optimally debulked stage III disease-optimal debulking in this study was defined as residual cancer $\leq 1 \mathrm{~cm}$ - to a regimen of IV cisplatin and paclitaxel or a regimen of IV carboplatin followed by IP cisplatin and paclitaxel. ${ }^{9}$ In this study, progression-free survival was 27.9 months in the IP arm and 22.2 months in the IV arm, with a $\mathrm{p}$-value of 0.01 . However, although the overall survival for the IP arm was 63.2 months and 52.2 months for the IV arm, this did not achieve statistical significance, with a one-tailed $\mathrm{p}$-value of 0.05. Furthermore, patients experienced significant toxicities with the IP regimen in this study and critics argued that patients in the IP arm also received an increased dose of chemotherapy due to the addition of IV carboplatin. Recently a third phase III randomized trial was published comparing IP versus IV chemotherapy for patients with optimally debulked ovarian cancer. ${ }^{10}$ Four hundred and fifteen patients were randomized to paclitaxel $\left(135 \mathrm{mg} / \mathrm{m}^{2}\right.$ IV over 24 hours) day one and IV cisplatin $\left(75 \mathrm{mg} / \mathrm{m}^{2}\right)$ day two or to IV paclitaxel $\left(135 \mathrm{mg} / \mathrm{m}^{2}\right.$ IV over 24 hours) day one, IP cisplatin $\left(100 \mathrm{mg} / \mathrm{m}^{2}\right)$ day two and IP paclitaxel $\left(60 \mathrm{mg} / \mathrm{m}^{2}\right)$ day eight. An overall survival of 65.6 months was observed in the IP/IV arm versus 49.7 months in the IV arm, with a p-value of 0.03 . Based

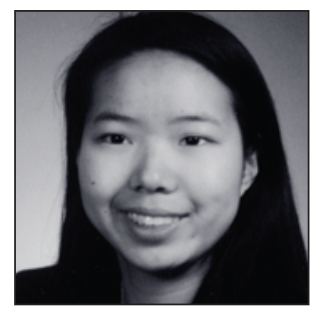

Joyce Liu, MD, is currently a second-year fellow in Medical Oncology at Dana Farber Cancer Institute. She obtained her undergraduate and medical degrees from Harvard University and completed her residency in Internal Medicine at Brigham and Women's Hospital.

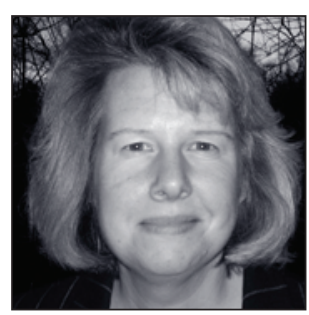

Ursular Matulonis, MD, is the Director of Medical Gynecologic Oncology at the Dana-Farber Cancer Institute in Boston, MA. She is also an Assistant Professor of Medicine at Harvard Medical School in Boston. Her research interests include testing new therapeutic agents for the treatment of newly diagnosed and relapsed ovarian cancer, the impact of age on treatment, and the biology of ovarian cancer, and medical decision-making and quality of life in ovarian cancer patients. 
upon this result, the National Cancer Institute (NCI) issued a clinical announcement stating that women with optimally debulked stage III ovarian cancer should be counseled about the clinical benefit associated with a combined regimen of IV and IP chemotherapy and that IP/IV chemotherapy is the preferred method of chemotherapy delivery in the optimally cytoreduced patient. ${ }^{11}$

Despite the outcomes of the three published phase III trials, controversy remains over the role of IP chemotherapy as first-line treatment for optimallydebulked advanced ovarian cancer. ${ }^{12}$ However, a recent meta-analysis of all trials comparing IP to IV chemotherapy did demonstrate a survival benefit in favor of IP regimens. ${ }^{13}$ Based upon the evidence currently available and the survival benefit observed with IP chemotherapy, we believe that IP chemotherapy should be considered for patients with optimally debulked advanced disease. Patients must be counseled of the significant survival benefits now observed in three randomized trials. Toxicities do exist with IP chemotherapy, but progress has also been made with supportive care in oncology with improved antiemetics and growth factor use. Currently, additional clinical trials are in process to better evaluate the side effects associated with IP chemotherapy, and to assess the efficacy of other agents administered intraperitoneally, such as carboplatin. cisplatin/cyclophosphamide group $(p=0.01)$, and overall survival was significantly longer in the cisplatin/paclitaxel arm-38 months versus 24 months, $p<0.001$. The benefits of paclitaxel were confirmed in a second randomized phase III trial. ${ }^{15}$ Several randomized trials have demonstrated that carboplatin can be substituted for cisplatin with equal efficacy and less toxicity. ${ }^{16-18}$ Based upon these results, a carboplatinbased regimen including paclitaxel has been considered the standard of care for systemic chemotherapy for advanced ovarian cancer. A recent study by the Scottish Gynecological Cancer Trials Group (the SCOTROC study) suggests that a regimen of docetaxel and carboplatin appears to be similar to that of paclitaxel and carboplatin in terms of survival, although the toxicity profiles differ. ${ }^{19}$

\section{Neoadjuvant Chemotherapy and Secondary Surgical Cytoreduction}

For patients in whom an attempt at debulking surgery cannot be performed because of the morbidity and possible mortality of the surgery or because an attempt at debulking has been made but failed, neoadjuvant chemotherapy is an appropriate consideration for disease palliation and possible future surgery. Currently, there are no data that clearly demonstrate a survival benefit to this approach. In a study conducted by the European Organisation for Research and Treatment of

\section{Despite the outcomes of the three published phase III trials, controversy remains over the role of IP chemotherapy as first- line treatment for optimally debulked advanced ovarian cancer.}

\section{Intravenous Chemotherapy for Newly Diagnosed Patients}

For patients who are suboptimally debulked (residual cancer $>1 \mathrm{~cm}$ ), are felt to be poor candidates for IP therapy, i.e. older patients, those with poor renal function, and/or who decline IP treatment, IV chemotherapy remains the choice of treatment. In 1996, McGuire et al. established the superiority of combination platinum and paclitaxel for systemic treatment of advanced ovarian cancer. ${ }^{14}$ In this study, 410 patients with suboptimally debulked (residual disease $>1 \mathrm{~cm}$ ) stage III or IV disease were randomized to either IV cisplatin and cyclophosphamide or IV cisplatin and paclitaxel. Response rates were $73 \%$ in the cisplatin/paclitaxel group compared with $60 \%$ in the
Cancer (EORTC), patients with suboptimally debulked ovarian cancer were randomized to receive either six cycles of chemotherapy with cisplatin and cyclophosphamide alone, or three cycles of chemotherapy upfront, then interval debulking surgery, followed by three additional cycles of chemotherapy. ${ }^{20}$ In this study, survival was improved by six months for patients who received interval debulking surgery-26 months versus 20 months, $\mathrm{p}=0.012$.

However, in a similar study performed by GOG in which all surgeries were performed by gynecological oncology surgeons, no improvements in either diseasefree or overall survival between patients randomized between interval cytoreduction or no surgery were observed. ${ }^{21}$ EORTC is currently comparing 
neoadjuvant chemotherapy with interval debulking surgery to primary debulking surgery. ${ }^{22}$ At the present time, neoadjuvant chemotherapy cannot be considered an appropriate substitute for optimal primary debulking surgery, especially given the potential benefits of primary debulking surgery. These include symptom improvement, establishment of stage and pathological diagnosis, removal of poorly vascularized cancer, and the possibility of enabling the patient to proceed with IP chemotherapy. However, in appropriate patients who are unable to undergo primary optimal debulking surgery, the use of neoadjuvant platinum-based therapy with interval cytoreduction may be considered.

\section{Maintenance Chemotherapy}

For patients who achieve remission following primary treatment, maintenance chemotherapy has been tested in order to possibly delay disease recurrence and prolong overall survival. In a phase III trial, 277 patients with advanced ovarian cancer who had achieved clinical remission following first-line chemotherapy were randomized to receive either three or 12 cycles given once a month of single agent IV paclitaxel as maintenance therapy. ${ }^{23}$ Results demon-strated a sevenmonth improvement in progression free survival-28 months versus 21 months, $p=0.0035$ ) - but no differences in survival. GOG is currently actively enrolling patients to a study randomizing women in cancer recurs, it is considered incurable, the cancer becomes increasingly chemotherapy resistant and the focus of further therapy becomes palliative. The platinum-free interval (PFI)-defined as the time between the last cycle of platinum and evidence of disease progression-is an important predictor of outcome and response to further treatment. In a retrospective analysis of 72 patients treated initially treated with a platinum-based regimen, Markman et al. found that PFI of 5-12 months, 13-24 months, and greater than 24 months resulted in response rates to repeat platinum-based therapy of $27 \%, 33 \%$, and $59 \%$, respectively. ${ }^{26}$ Given the importance of the PFI in predicting response, GOG has defined the following clinical situations:

- platinum-resistant disease as a PFI of less than six months following platinum-based therapy;

- platinum-refractory disease as progression of cancer during platinum-based therapy; and

- platinum-sensitive disease as a PFI of greater than six months after a platinum-based regimen.

It is noteworthy that, even in patients with initially platinum-sensitive disease at recurrence, the platinum-free interval shortens with each subsequent treatment with platinum, eventually evolving into platinum-resistant disease with lowered overall response rates to chemotherapy. ${ }^{27}$

\section{It is important to regard recurrent ovarian cancer as two separate entities, platinum-sensitive disease and platinum-resistant disease.}

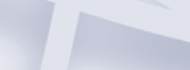

clinical remission to three possible treatments:

- placebo;

- paclitaxel once monthly for 12 months; or

- paclitaxel poliglumex, a novel formulation of paclitaxel, once monthly for 12 months. ${ }^{24}$

The results of this study will help further define the benefits, if any, of maintenance chemotherapy.

\section{Recurrent Ovarian Cancer}

Response to first-line platinum-based therapy in the patient with advanced ovarian cancer is up to $80 \%$ but, despite this initial response, the disease will recur in the majority of these patients. ${ }^{14,25}$ Once ovarian
Treatment of Platinum-Sensitive Cancer

Single-agent cisplatin and carboplatin are US Food and Drug Administration (FDA) -approved for the treatment of recurrent ovarian cancer. Response rate to these agents as single therapy in platinum-sensitive disease is up to $50 \%$, and degree of response will depend on the length of the platinum-free interval. ${ }^{28,29}$ Carboplatin and cisplatin appear to have equivalent response rates in the recurrent setting as in the upfront treatment setting but their toxicity profiles differ. Nonplatinum single agents have also been studied in the setting of platinum-sensitive disease. Phase III trials including the use of single-agent paclitaxel, topotecan or pegylated liposomal doxorubicin (PLD) have demonstrated an approximately $20-30 \%$ response rate 
in patients with platinum-sensitive disease. ${ }^{30,31}$

Whether platinum-based combination therapy is superior to single-agent therapy in platinum-sensitive disease remains under investigation. Two large randomized phase III clinical trials and a randomized phase II clinical trial have suggested that combination chemotherapy with platinum and paclitaxel may be superior to that with single-agent platinum alone, and a separate randomized phase III trial also suggests increased benefit from adding gemcitabine to carboplatin. ${ }^{32-34}$ However, criticisms of these trials include the relatively low number of patients who had received a taxane during their initial therapy, as well as questions regarding the possible role of sequential therapy in comparison to combined therapy.

Treatment of Platinum-Resistant Disease

Patients with platinum-resistant or platinum-refractory disease carry a poor prognosis. Phase II data suggest response rates in the $20 \%$ or less range for single-agent therapies, and randomized phase III trials in patients with platinum-resistant disease report response rates of 6-13\% with a median time-to-progression of two to three months. ${ }^{30,31}$ There are scant randomized data to provided guidance for therapy in the setting of platinum-resistant disease. In general, due to the increased toxicities associated with and lack of data supporting superiority of combination therapy, single-agent therapy is used for the treatment of platinum-resistant disease. Drugs active in this setting include paclitaxel, docetaxel, pegylated liposomal doxorubicin (PLD), topotecan, oral etoposide, gemcitabine, vinorelbine, ifosfamide, and tamoxifen or other anti-estrogen therapies including aromatase inhibitors. $^{35-54}$ No one chemotherapy drug, however, appears to be superior.

\section{Novel Therapies}

Bevacizumab is currently under active investigation as an agent in both primary and recurrent advanced ovarian cancer. Response rates for bevacizumab in both platinum-sensitive and resistant ovarian cancer patients in the recurrent setting approach $16 \% .^{55,56}$ Recently, an overall response rate of $16 \%$ was reported in a patient population who were platinum-refractory and had either progressed through topotecan or PLD, but the trial closed early due to a higher than expected rate of gastrointestinal perforations of $11 \%$. Currently, trials are enrolling investigating bevacizumab in both settings, including a large randomized phase III trial examining the role of bevacizumab in initial therapy in combination with carboplatin and paclitaxel..$^{57}$

\section{Sum mary}

The National Comprehensive Cancer Network (NCCN) has published guidelines on the treatment of advanced ovarian cancer, including recurrent disease. ${ }^{58}$ In the primary setting, maximal cytoreductive surgery plays an important role. Subsequent chemotherapeutic options include intra-peritoneal chemotherapy, and recent data emphasize the importance of considering this option in patients with small residual disease volume, i.e. $\leq 1 \mathrm{~cm}$ residual. Other questions that continue to be addressed include the utility of neoadjuvant surgery and interval debulking, as well as the benefits of maintenance chemotherapy.

Despite an up to $80 \%$ response rate to initial therapy, a large proportion of advanced ovarian cancer will recur. It is important to regard recurrent ovarian cancer as two separate entities, platinum-sensitive disease and platinumresistant disease. For patients where systemic therapy is an option, chemotherapy is indicated for either the prevention or treatment of symptoms resulting from ovarian cancer. Patients with platinum-sensitive recurrent ovarian cancer who have longer PFIs should be considered for platinum-taxane regimens unless previous toxicities preclude their use. Otherwise, for the asymptomatic or minimally asymptomatic patient, single agent therapy should be used depending on the degree of platinum sensitivity, previous toxicities, route of administration and avoidance of certain toxicities as requested by the patient. In patients with platinumresistant cancer, response rates of chemotherapy drugs are less than in patients with platinum-sensitive cancers. No one drug appears to be superior in the setting of platinum-resistant ovarian cancer.

\section{References}

1. Jemal A, Siegel R, Ward E, et al., CA Cancer J Clin (2006);56: pp. 106-130.

2. Parkin DM, Bray F, Ferlay J, et al., Natl Cancer Inst Monogr (1975);42: pp. 101-104.

4. Bristow RE, Tomacruz RS, Armstrong DK, et al., J Clin Oncol (2002);20(5): pp. 1248-1259.

5. Eisenkop, S.M, Spirtos NM, Gynecol Oncol (2001);82(3): pp. 489-497.

6. Omura GA, Brady MF, Homesley HD, et al., J Clin Oncol (1991);9(7): pp. 1138-1150.

7. Casper ES, Kelsen DP,Alcock NW, et al., Cancer Treat Rep (1983);67(3): pp. 235-238.

8. Alberts DS, Liu PY, Hannigan EV, et al., N Engl J Med (1996);335(26): pp. 1950-1955. 
9. Markman M, Bundy BN, Alberts DS, et al., J Clin Oncol (2001);19(4): pp. 1001-1007.

10. Armstrong DK, Bundy B, Wenzel L, et al., N Engl J Med (2006);354: pp. 34-43.

11. "NCI Clinical Announcement: Intraperitoneal chemotherapy for ovarian cancer." Available at http://ctep.cancer.gov/highlights/ovarian.html. Last accessed on November 11, 2006.

12. Gore M, du Bois A, Vergote I, J Clin Oncol (2006);24(28): pp. 4528-4530.

13. Jaaback K, Johnson N, Cochrane Database Syst Rev (2006);(1): p. CD005340.

14. McGuire WP, Hoskins WJ, Brady MF, et al., N Engl J Med (1996);334: pp. 1-6.

15. Piccart MJ, Bertelsen K, James K, et al., J Natl Cancer Inst (2000); 92(9): pp. 699-708.

16. Neijt JP, Engelholm SA, Tuxen MK, et al., J Clin Oncol (2000);18(17): pp. 3084-3092.

17. Ozols RF, Bundy BN, Greer BE, et al., J Clin Oncol (2003); 21(17): pp. 3194-200.

18. du Bois A, Luck HJ, Meier W, et al., J Natl Cancer Inst (2003);95(17): pp. 1320-1329.

19. Vasey PA, Jayson GC, Gordon A, et al., J Natl Cancer Inst (2004);96(22): pp. 1682-1691.

20. van der Burg ME, van Lent M, Buyse M, et al., N Engl J Med (1995);332(10): pp. 629-634.

21. Rose PG, Nerenstone S, Brady MF, et al., N Engl J Med (2004);351(24): pp. 2489-2497.

22. Phase III Randomized Study of Neoadjuvant Chemotherapy Followed By Interval Available at

http://www.cancer.gov/clinicaltrials/EORTC-55971. Last accessed on November 11, 2006.

23. Markman M, Liu PY, Wilczynski S et al., J Clin Oncol (2003);21(13): pp. 2460-2465.

24. Liu J, Matulonis U, J Natl Compr Cancer Network (2006);4(9): pp. 947-953.

25. Ozols RF, Bundy BN, Greer BE, et al., J Clin Oncol (2003);21(17): pp. 3194-3200.

26. Markman M, Rothman R, Hakes T, et al., J Clin Oncol (1991);9(3): pp. 389-393.

27. Markman M, Markman J, Webster K, et al., J Clin Oncol (2004);22(15): pp. 3120-3125.

28. Gore ME, Fryatt I, Wiltshaw E, et al., Gynecol Oncol (1990);36(2): pp. 207-211.

29. Bolis G, Scarfone G, Giardina G, et al., Gynecol Oncol (2001); 81: pp. 3-9.

30. Huinink WTB, Gore ME, Carmichael J, et al., J Clin Oncol (1997);15(6): pp. 2183-2193.

31. Gordon AN, Fleagle JT, Guthrie D, et al., J Clin Oncol (2001);19(14): pp. 3312-3322.

32. The ICON and AGO Collaborators, Lancet (2003);361: pp. 2,099-2106.

33. Gonzalez-Martin AJ, Calvo E, Bover I, et al., Ann Oncol (2005)16(5): pp. 749-755.

34. Pfisterer J, Vergote I, Du Bois A, et al., Int J of Gynecol Cancer (2005);15(s1): pp. 36-41.

35. McGuire WP, Rowinsky EK, Rosenshein NB, et al., Ann Intern Med (1989);111: pp. 273-279.

36. Einzig AI., Wiernik PH, Sasloff J, et al., J Clin Oncol (1992);10(11): pp. 1748-1753.

37. Markman M, Hall J, Spitz D, et al., J Clin Oncol (2002);20(9): pp. 2365-2369.

38. Markman M, Zanotti K, Webster K, et al., Gynecol Oncol (2003);91: pp. 573-576.

39. Rose PG, Blessing JA, Ball HG, et al., Gynecol Oncol (2003);88: pp. 130-135.

40. Muggia FM, Hainsworth JD, Jeffers S, et al., J Clin Oncol (1997);15(3): pp. 987-993.

41. Gordon AN, Granai CO, Rose PG, et al., J Clin Oncol (2000);18(17): pp. 3093-3100.

42. Markman M, Kennedy A, Webster K, et al., Gynecol Oncol (2000);78(3): pp. 369-372.

43. Kudelka AP, Tresukosol D, Edwards CL, et al., J Clin Oncol (1996);14(5): pp. 1552-1557.

44. Creemers J, Bolis G, Gore ME, et al., J Clin Oncol (1996);14(12): pp. 3056-3061.

45. de Wit R, van der Burg MEL, v.d. Gaast A et al., Ann Oncol (1994);5: pp. 656-657.

46. Rose PG, Blessing JA, MayerAR, et al., J Clin Oncol (1998);16(2): pp. 405-410.

47. D'Agostino G, Amant F, Berteloot, P et al., Gynecol Oncol (2003);88(3): pp. 266-269.

48. Markma M., Webster K, ZanottiK, et al., Gynecol Oncol (2003);90: pp. 593-596.

49. Bajetta E, Di Leo A, Biganzoli L, et al., J Clin Oncol (1996):14(9): pp. 2546-2551.

50. Sorenson P, Moyer M, Jakobsen A, et al., Gynecol Oncol (2001);81: pp. 58-62.

51. Markman M, Hakes T, Reichman B, et al., J Clin Oncol (1992);10(2): pp. 243-248.

52. Markman M, Kennedy A, Sutton G, et al., Gynecol Oncol (1998) 70:pp. 272-274.

53. Perez-Gracia JL, Carrasco EM, Gynecol Oncol (2002); 84: pp. 201-209.

54. del Carmen MG, Fuller AF, Matulonis UA, et al., Gynecol Oncol (2003);91(3): pp. 596-602.

55. Monk BJ, Han E, Joseph-Cowan CA, et al., Gynecol Oncol (2006): p. Article in press; Epub June 212006.

56. Cannistra SA, Matulonis UA, Penson RT, et al., J Clin Oncol (2006); ASCO Annual Meeting Proceedings, (2006); 24(18S): p. Abst 5006.

57. Carboplatin and Paclitaxel With or Without Bevacizumab in Treating Patients With Stage III or Stage IV Ovarian Epithelial or

Primary Peritoneal Cancer. Available at http://clinicaltrials.gov/ct/gui/show/NCT00262847?order=100. Last accessed on

November 11, 2006.

58. National Comprehensive Cancer Network, (2006). 